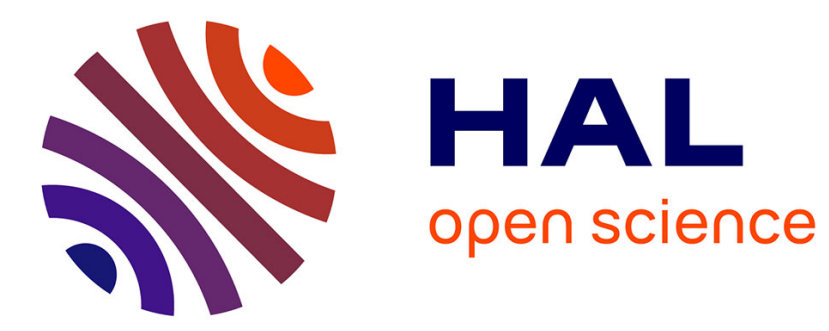

\title{
Notetaking and Writing from Hypertexts in L1 and L2
}

\author{
Marie-Laure Barbier, Annie Piolat, Jean-Yves Roussey, Françoise Raby
}

\section{To cite this version:}

Marie-Laure Barbier, Annie Piolat, Jean-Yves Roussey, Françoise Raby. Notetaking and Writing from Hypertexts in L1 and L2. International Journal of Applied Linguistics, 2008, 156, pp.31 - 50. 10.1075/itl.156.04bar . hal-01488600

\section{HAL Id: hal-01488600 \\ https://hal-amu.archives-ouvertes.fr/hal-01488600}

Submitted on 16 Mar 2017

HAL is a multi-disciplinary open access archive for the deposit and dissemination of scientific research documents, whether they are published or not. The documents may come from teaching and research institutions in France or abroad, or from public or private research centers.
L'archive ouverte pluridisciplinaire HAL, est destinée au dépôt et à la diffusion de documents scientifiques de niveau recherche, publiés ou non, émanant des établissements d'enseignement et de recherche français ou étrangers, des laboratoires publics ou privés. 


\title{
NOTETAKING AND WRITING FROM HYPERTEXTS IN L1 AND L2: COGNITIVE EFFORT AND LANGUAGE PROCEDURES
}

\author{
Marie-Laure Barbier \\ Annie Piolat \\ Jean-Yves Roussey \\ Université de Provence \\ Françoise Raby \\ Université Stendhal Grenoble III
}

ABSTRACT

This study analyzes the cognitive effort and linguistic procedures of sixty students using information taken from an experimental website in L1 (French) and in L2 (English). The students navigated on the website and took notes on paper or with a word processor. A triple-task paradigm was used to estimate the cognitive load of reading, notetaking, and writing processes in L2. The students had to perform two additional tasks while a main task (notetaking, for example) was being carried out. They had to react as fast as possible to sound signals sent out at random intervals. They also had to identify what they were doing at the time the sound signal was heard (reading, notetaking, or writing). The study focuses on the way the students managed their cognitive resources while exploring the website, selecting and writing down the ideas they considered useful, and reconstructing them later when producing their own text. Surprisingly, no difference in cognitive load was observed between L1 and L2. By relying almost exclusively on the copy and paste functions to retrieve information from the website, the participants using a word processor in L2 succeeded in making reading a less costly activity, and they performed similarly to the notetakers in L1. The students' difficulties in L2 became apparent only in the paper condition. The strategies and linguistic procedures of the students are described and related to the ways teachers can approach the new dimensions of notetaking and writing with a computer. 
Descriptive empirical studies

\section{Introduction}

In second-language (L2) classes, teachers take advantage of new technologies such as the Internet and the World Wide Web. Learners' motivation is higher in this type of environment, which is more contextualized and interactive (Raby, 2005). However, the use of new technologies in school requires students to learn new modes of reading, notetaking and writing. Reading in hypertext mode appears to be more complex than in the traditional, linear mode (DeStefano \& LeFevre, 2007; Rouet, 2003). Writing with a computer (especially a word processor) can increase a learner's motivation to write, but it focuses the writer's attention on superficial aspects of the text, and thereby draws it away from the structure and coherence of the text's content (Barbier, Piolat, \& Roussey, 1998). Thus, research into reading and writing on the computer is highly important in computer-assisted language learning or CALL (Raby, 2005).

Notetaking is a skill not traditionally taught in school. However, this skill is accorded more and more importance owing to the use of computers in class, particularly when teachers are confronted with excessive use of the copy and paste functions and the difficulties encountered by their pupils in integrating selected information. The utility of teaching this skill is strengthened by research data which point out the importance of notetaking in knowledge learning (Piolat, Barbier, \& Roussey, 2008; Titsworth \& Kiewra, 2004). The present study investigates how website users process written language through notetaking in $\mathrm{L} 2$. From a cognitive perspective, our aim is to understand how these users coordinate their processes and mental resources to manage the information they read, and how they use it to elaborate a new text. A great deal of research has been carried out in recent years on hypertext documents and information retrieval in native languages (DeStefano \& LeFevre, 2007; Rouet, 2003). Yet, studies on the use of hypertexts in $L 2$ are less abundant, and those analyzing the real-time integration of three cognitive activities - reading, notetaking, and writing - are even scarcer (but see Barbier, 2006; Piolat, Olive, \& Kellogg, 2005). The three main issues adressed in this study are: (1) cognitive load and strategies developed by L2 learners when taking notes from a website, (2) the effect of the medium used for notetaking (paper or word processor), and (3) the most useful indicators for teachers in a school setting to allow them to better track the cognitive difficulties of their pupils.

Some studies have reported that L2 notetaking, like L2 writing, is much more resourcedemanding than in L1, with lower performance caused by poorer linguistic control (Chaudron, Loschky, \& Cook, 1994; Clerehan, 1995; Faraco, Barbier, \& Piolat, 2002; Barbier, Piolat, Roussey, \& Olive, (2006). In some of these studies, the triple-task paradigm was used to estimate the cognitive cost of the $\mathrm{L} 2$ writing processes. This paradigm requires the participant to carry out two additional tasks while they are performing a main task. For example, during notetaking, students are required to react as fast as possible (by pressing on the computer touchpad) to sound signals randomly produced at irregular intervals (Olive, Kellogg, \& Piolat, 2002), in addition to having to record what they were doing when the sound signal was heard (reading, notetaking, or writing). Reaction time (RT) in this triple-task situation, is compared to a control condition in which participants only have to react to sound signals. The added reaction time during the main task measures the cognitive cost of reading, notetaking, or text elaboration. 
The longer the reaction time, the greater the resources allocated in working memory.

In one of these studies (Barbier \& Piolat, 2005), cognitive effort allocated to notetaking in L2 was not as great as that allocated to $L 2$ writing when the notetaking was done from an oral speech source. What might be observed if notes are taken from a website? Several findings on the constraining effects of hypertext documents are already available. Reading becomes more complex (Baccino, 2004; Rouet, 2003) because of a supplementary decision process about what links to choose, and memory retention of all potential links in case of a return to the text. In $L 1$, hypertext reading appears to demand more resources from working memory (DeStefano \& LeFevre, 2007) and to affect the quality of notes (Gérouit, Piolat, Roussey, \& Barbier, 2001), which tend to be less voluminous than when a paper document is read. What are the consequences of using this type of document on the cognitive process of notetaking in $\mathrm{L} 2$, since hypertext processing already turns out to be more difficult in one's native language ? Does the medium used for notetaking (paper or a word processor) also influence the process? If so, there could be some implications for teaching notetaking and writing on the computer in the L2 classroom.

With these questions in mind, the following objectives were set for this study. (1) Our first aim was to analyze the effect of the language and mediums used on the strategies developed for hypertext exploring. Specifically, the participants were expected to have different exploratory strategies depending on the language. Exploration should be more resource-demanding in $L 2$, which should give rise to fewer number of pages explored, longer times spent browsing website pages, and greater reaction times on the added tasks, at least for the reading process. (2) Our second aim was to analyse the effect of languages and mediums on the linguistic processes used during notetaking. Accordingly, the selection process (number of conceptual units noted), lexical accuracy (number of words identical to those in the Web source), lexical transformations (number of abbreviated words), the number of words noted, and notetaking speed (number of words noted per minute) should be smaller in L2. Also, notetaking using a word processor was expected to be more complex, so results on the various indicators should be poorer than for notetaking on paper, except for the size of the noted units and whether they are the same as in the source text, since word processing facilitates verbatim reproduction of text through the "copy and paste" function. (3) Our third aim was to verify whether notetaking and writing in $\mathrm{L} 2$, and working in a word processing, constitute the most costly situations in cognitive terms. Thus, the reaction times for notetaking and writing should be the longest in L2 using a word processor, and the shortest in L1 on paper. It was also expected that in L1, the texts would be longer and the ideas more structured and modified compared to the original state of the information on the website. 
Descriptive empirical studies

\section{Method}

\section{Participants}

Sixty-two graduate students of education at the University of Provence participated in the experiment in French (L1) or in English (L2). Their average age was 26. Their proficiency in English was assessed using a language experience questionnaire, and their working-memory capacity in reading was evaluated using a reading span test in French and in English. Half of them took notes on paper and the other half used a word processor. The participants were randomly assigned to the two experimental conditions, so they carried out one task each, either in L1 or L2, in the Pen and Paper (PP) or Word Processor (WP) condition.

\section{Material}

The language experience questionnaire included the profile of the participants (age, gender, and nationality), their experience with the computer and notetaking, and their linguistic experience (number of languages studied or spoken, age at which they began learning English, etc.). The questionnaire also asked the participants to evaluate their oral and written skills in English. A common way of estimating linguistic skills in L2 is to look at participants' self-assessments. Ross (1998), who reviewed more than 60 studies, pointed out the importance of this indicator. He systematically compared the self-assessments of participants, their linguistic skills in L1 and in L2, and the data on their actual results. For all language activities considered, he found a mean correlation of .63 (.61 for reading comprehension, .65 for listening comprehension, .55 for speaking, and .52 for writing). Self-assessment is thus a relevant source of information for identifying the skills of participants, for all linguistic dimensions.

Because this study focuses mainly on attentional resources allocated to reading and notetaking processes, working memory capacity in reading was evaluated for each participant. They performed reading span tests adapted to French as their first language (Desmette, Hupet, Schelstraete, \& Van der Linden, 1995) and to English as their second language (Hannon \& Daneman, 2001). The analysis of individual differences related to working memory capacities are not presented in this article, but descriptive statistics about performance on the reading span tests are presented in the results section. In both languages, the reading span test lasted approximately 15 minutes. Participant were asked to read aloud series of sentences at their own pace without interruption. They also had to remember the last word of each sentence and recall them all every time a blank sheet appeared. The test was organized into three series, with five blocks of sentences in each. The first block contained two sentences (with two words to recall) and the fifth block contained six sentences. In this study, the number of correctly recalled words was used as a measure of reading span, as recommended by Friedman and Miyake (2005) in their comparative work on methods of estimating reading span. 
The experimental website was taken from the United Nations website and included a description of a world conference against racism and discrimination in 2001 (http://www.un.org/ WCAR/; see examples of website sections in the Appendix). The site was chosen because it was multilingual and therefore offered the opportunity to present strictly identical versions of the text in French and English, from the standpoint of both format and content. However, the site was adapted and simplified because the task had to last 15 minutes. Out of the 20 initial pages, there were 11 pages consisting of the topics, objectives, schedule, and organization of the conference, among other things.

Participants' web navigation was recorded using ARI software (Blondel, Le Touzé, \& Tarizzo, 2002). This software assists students in retrieving information from the Internet and is adapted to a school environment. It includes a tracer that was used for the present study. SCRIPTKELL software (Piolat, Olive, Roussey, Thunin, and Ziegler, 1999) was used to measure reaction times and to categorize the ongoing process while participants looked for and noted website information. This software allows the experimenter to send out a sound signal at a chosen pace. The computer also recorded each reaction time (in milliseconds) and the key selected by the participant ("I'm reading", "I'm taking notes" or "I'm writing"). At the end of the experiment, the software calculated the baseline reaction times (by computing the average basic reaction time measured during the training). The average of the baseline reaction times could then be obtained for reading, notetaking, and composing the text. Finally, Inputlog Software (Van Waes \& Leijten, 2006) was used as a logging tool to analyze the input modes of the keyboard and mouse, and to describe the online notetaking processes implemented on the word processor.

\section{Procedure}

The experiment lasted for approximately one-and-a-half hours. After filling out the questionnaires and performing the reading span tests, the participants were asked to carry out three tasks. The first task required responding to sound signals as quickly as possible. The SCRIPTKELL software randomly sent out 30 signals at variable intervals ranging from 5 to 15 seconds (the first 5 signals served as practice signals; the remaining 25 were used to compute the average basic reaction time). For the second task, the participants were informed that they would have to perform the task in French or English. The following instructions were visible throughout the experiment: "You work at the United Nations and you have to inform an American journalist, a specialist on human rights, about the organization of a world conference against racism. The objective is to invite this journalist to the conference, and to give him all the information needed to attend the conference (aims, topics, participants, access modalities, etc.). You will look for information about this conference on the website. You have 15 minutes to read and take notes from this document. Afterwards, you will have 15 more minutes to write your letter to the journalist, while no longer consulting the website, using the same medium as for the notetaking (on paper or with a word processor)."

The participants had to look for information on the experimental website and take notes with a word processor or on paper, using as many sheets as they needed. In addition to this main 
Descriptive empirical studies

task, they had to react as fast as possible to the sound signals, distributed at random intervals ranging from 15 to 45 seconds. After each reaction to the sound signal, they had to indicate what they were doing when the signal interrupted them. To do so, they pressed a key on the keyboard labelled "reading" or "notetaking". For the third task, the participants had to write the letter in no more than 15 minutes, on paper or with a word processor, depending on the experimental condition. They could use their notes, but could not consult the website again. During the writing process, they had to react as quickly as possible to the sound signals.

\section{Dependent Variables}

Analysis of the variables collected in this experiment concerned the effect of the language and medium used on the activity carried out by the participants (reading, notetaking, or writing). Three types of dependent variables were taken into account during the analysis: the cognitive resources assigned to reading, notetaking, or writing, assessed by reaction time on the secondary task, and by notetaking and writing productivity (average number of words produced per minute); the website exploration process, assessed by the number of pages browsed, and the average page-exploration time; and the notetaking procedures used in each medium (paper or word processor), such as selection process (number of conceptual units noted), lexical accuracy (number of words identical to those in the web source), lexical transformation (number of abbreviated words), and the use of retrieved information in the written text (number of ideas). A conceptual unit was defined as one or more pieces of information about the same topic (Faraco et al., 2002). For the writing process (syntactic organization of the text), connectives were taken as relevant indicators for identifying boundaries between utterances. For notetaking, several isolated items not embedded in a clause or a phrase were taken as conceptual units if the same conceptual unit existed in the source document. In many cases, sentences were copied verbatim from the website, which made them easier to detect.

\section{Results}

Analyses of variance were conducted on each variable with language (French as L1 or English as L2) and medium (paper or word processor) as between-participant factors. The analyses are presented below, after a description of the participants, their oral and written self-assessments in $L 2$, the results of the reading span tests, and their experience in using the Internet and office software. 


\section{Descriptive Statistics for Groups L1 and L2}

Table 1: Descriptive statistics concerning the students' age, linguistic experience, reading span, and computer use in L1 and L2.

\begin{tabular}{|c|c|c|c|c|}
\hline Variable & Average & $\begin{array}{l}\text { Standard } \\
\text { Deviation }\end{array}$ & Min & Max \\
\hline \multicolumn{5}{|c|}{ Group L1 ( $n=32$ ): reading, notetaking, and writing activities in L1 (French) } \\
\hline Age (Years) & 25 & 3.5 & 22 & 38 \\
\hline Percentage of correct answers on span test in L1 & 75 & 9 & 60 & 90 \\
\hline Frequency of use of office software & 2.6 & 1.2 & 1 & 4 \\
\hline Frequency of Internet use & 2.6 & 1.4 & 1 & 4 \\
\hline Frequency of notetaking in L1 & 2.6 & 1.3 & 1 & 4 \\
\hline \multicolumn{5}{|c|}{ Group L2 ( $n=30$ ): reading, notetaking, and writing activities in L2 (English) } \\
\hline Age (Years) & 27 & 5.4 & 21 & 43 \\
\hline Age at which English was first learned & 11 & 0.9 & 8 & 13 \\
\hline Oral self-assessment in L2 (out of 4) & 2.3 & 0.7 & 1 & 4 \\
\hline Written self-assessment in L2 (out of 4) & 2.6 & 0.8 & 1.5 & 4 \\
\hline Percentage of correct answers on span test in L1 & 75 & 09 & 55 & 88 \\
\hline Percentage of correct answers on span test in L2 & 65 & 12 & 47 & 88 \\
\hline Frequency of use of office software & 2.6 & 1.2 & 1 & 4 \\
\hline Frequency of Internet use & 2.4 & 1.2 & 1 & 4 \\
\hline Frequency of notetaking in $\mathrm{L} 1$ & 2.5 & 1.3 & 1 & 4 \\
\hline Frequency of notetaking in L2 & 2.5 & 1.2 & 1 & 4 \\
\hline
\end{tabular}

Using a questionnaire, participants in group L2 self-evaluated their use of office software and of the Internet, and their skills in English on a 4-point scale. The average ratings were 2.3 for oral self-assessment and 2.6 for written self-assessment. In their view, then, their English proficiency was rather advanced (see Table I).

The reading span test in French as L1 was used to measure the capacity of the participants' working memory. Participants in group L2 also took this test in English. For these participants, the results of the two tests were highly correlated $(r=.59, p<.05)$. On the other hand, the span test scores in English were not correlated with their written self-assessments $(r=-.07, p<.05)$. In other words, those who performed well on the span test in L1 were the same ones who excelled in L2, regardless of their perceived mastery of the language. All participants had an English proficiency level advanced enough for them to be able to read aloud at the same time as they memorized between $47 \%$ and $88 \%$ of the words in the reading span test (see Table I).

Finally, all of the participants said they used the computer quite frequently, whether for office software or the Internet. Their reports were also relatively consistent for their notetaking frequency in L1 and L2 (see Table 1). 
Descriptive empirical studies

\section{Cognitive Cost of Notetaking and Writing}

No significant effect of the language or medium used was found on reaction times. On the other hand, reaction times varied significantly with the task $(F(2,116)=44.12, p<.001$; see Table 2). Reading demanded more resources than writing $(F(1,60)=51.76, p<.001)$ and notetaking also demanded more resources than writing $(F(1,60)=83.84, p<.001$; see Table 2$)$. The difference between reading and notetaking was not significant.

A significant interaction between task and medium was also observed $(F(2,116)=9.80, p<.001$; see Figure 1). Reading was more costly in PP condition (mean=499) than in the WP condition (mean $=361 ; F(1,60)=10.91, p<.01)$. Reaction times during notetaking and writing did not vary significantly across mediums.

Table 2: Reaction time on the secondary task (in milliseconds), depending on the task, language and medium used by the participants (pen and paper (PP) or word processor (WP)).

\begin{tabular}{|l|c|c|c|c|c|}
\cline { 2 - 6 } \multicolumn{1}{c|}{} & \multicolumn{2}{c|}{ L1 } & \multicolumn{2}{c|}{ L2 } & \\
\cline { 2 - 6 } \multicolumn{1}{c|}{} & PP (sd) & WP (sd) & PP (sd) & WP (sd) & Mean \\
\hline Reading & $513(147)$ & $362(165)$ & $486(226)$ & $360(97)$ & $432(178)$ \\
\hline Note-Taking & $444(139)$ & $465(175)$ & $433(199)$ & $433(84)$ & $444(154)$ \\
\hline Writing & $306(122)$ & $288(140)$ & $320(143)$ & $273(92)$ & $298(125)$ \\
\hline Mean & $421(159)$ & $413(201)$ & $372(174)$ & $355(110)$ & \\
\hline
\end{tabular}

Sd: the standard deviation is shown in parentheses.

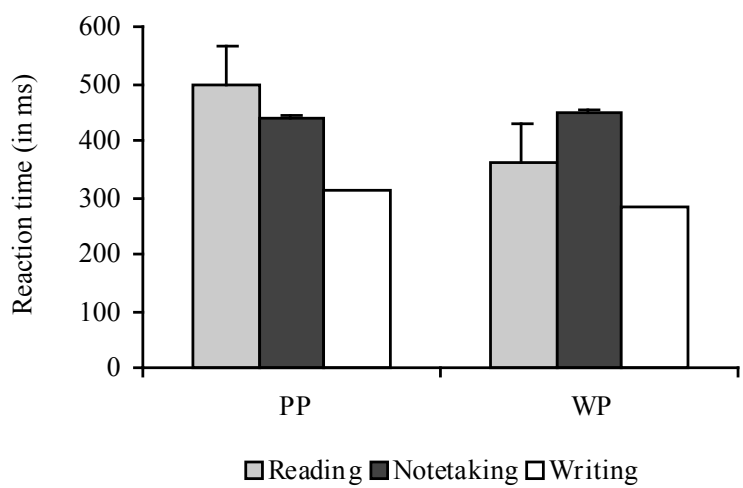

Figure 1: Reaction time on the secondary task (in milliseconds), by task (reading, notetaking, or writing) and medium (pen and paper (PP) or word processor (WP)).

Concerning productivity during notetaking, participants in the PP condition produced 
significantly fewer words per minute than in the WP condition (mean PP $=10$; mean WP $=104$; $F(1,58)=71.76, p<.001)$. The same was observed for writing (mean $P P=12.4$; mean WP $=36.6$; $F(1,58)=21.46, p<.001)$. No effect of language was observed for productivity in notetaking, or in writing.

Table 3: Productivity (number of words noted or written per minute), depending on the language and medium used by participants.

\begin{tabular}{|l|c|c|c|c|c|}
\cline { 2 - 6 } \multicolumn{1}{c|}{} & \multicolumn{2}{c|}{ L1 } & \multicolumn{2}{c|}{ L2 } & \multicolumn{1}{c|}{} \\
\cline { 2 - 6 } \multicolumn{1}{c|}{} & PP (sd) & WP (sd) & PP (sd) & WP (sd) & Mean \\
\hline Note-taking & $11(3)$ & $94(56)$ & $9(3)$ & $116(70)$ & $56(64)$ \\
\hline Writing & $15(4)$ & $37(27)$ & $10(2)$ & $36(32)$ & $24(23)$ \\
\hline Mean & $13(4)$ & $66(52)$ & $10(3)$ & $76(67)$ & \\
\hline
\end{tabular}

Sd: the standard deviation is shown in parentheses.

\section{Website Exploration}

Participants in the WP condition tended to browse more website pages than participants in the $P P$ condition (mean WP $=27.3$; mean $P P=21.1 ; F(1,58)=3.16, p<.08$ ). No further effects were observed for the variable "number of pages browsed".

An analysis of variance on the percentage of website pages browsed revealed a significant effect of the medium factor. Participants in the WP condition explored the website more extensively (mean $=86 \%$ ) than participants in the PP condition (mean $=69 \% ; F(1,58)=11.63$, $p<.001)$. It also showed a significant interaction between language and medium $(F(1,58)=6.39$, $p<.02$; see Table 4). In both groups, the participants did not automatically browse all the website pages. However, in the PP condition, the participants browsed the site less extensively in $L 1$ (mean $=60 \%$ ) than in $L 2$ (mean $=78 \% ; F(1,30)=5.95, p<.03$; see Table 4). The difference between the two languages was not significant in the WP condition.

An analysis of variance on the time spent exploring the content pages again revealed a significant effect of the medium. Participants in the WP condition (mean=115 s.) explored each website page longer than in the PP condition (mean=75 s.; $F(1,58)=12.21, p<.001)$. Moreover, the interaction between the medium and language was significant $(F(1,58)=4.31, p<.05)$. In the PP condition, there was a tendency for the $\mathrm{L} 2$ participants (mean=95 s.) to spend less time on each page than the L1 participants (mean=55s; $F(1,30)=3.82$, $p<.06$, see Table 4). The difference between the two languages in the WP condition is not significant.

Finally, as far as the time spent on the table-of-contents pages is concerned, which was included in the total notetaking time, the analysis indicated a significant effect of medium. The participants in the WP condition (mean $=22.5 \%$ ) spent significantly more time on these pages than those in the PP condition (mean=3.5\%; $F(1,58=63.95, p<.001)$. ) 
Descriptive empirical studies

Table 4: Percentage of website pages browsed and page exploration time (in seconds), depending on language and reading span.

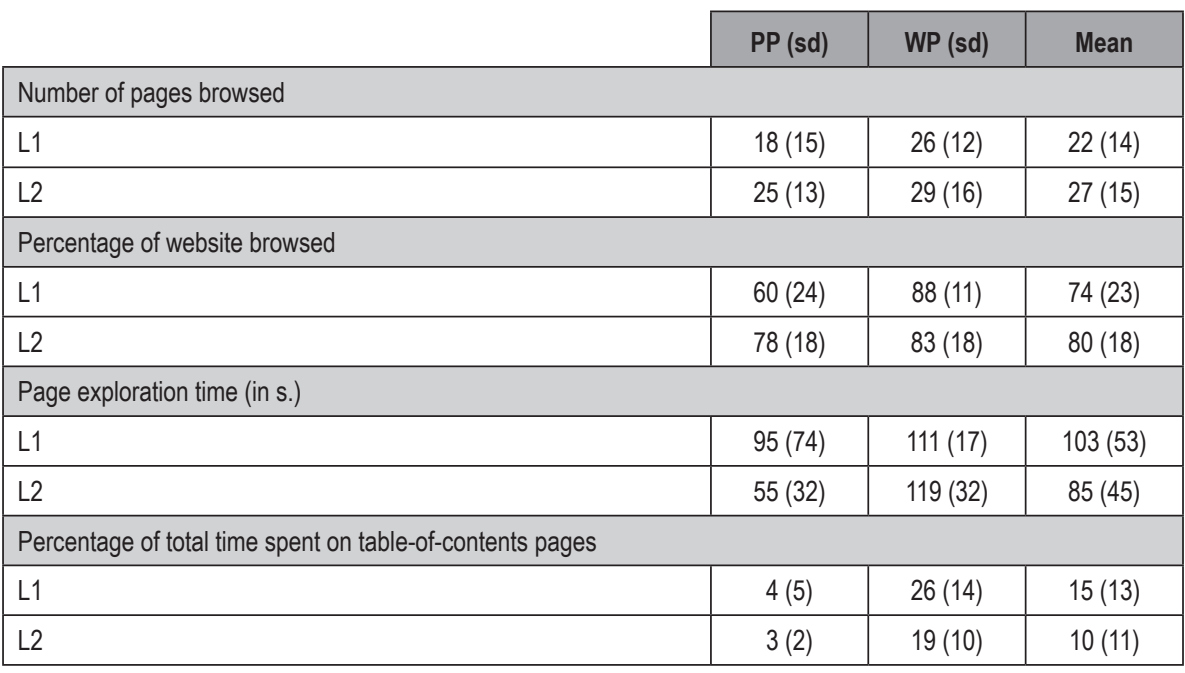

Sd: the standard deviation is shown in parentheses.

\section{Notetaking Processes}

In the WP notetaking condition, the majority of the words noted were copied and pasted from the experimental website. Only $10.5 \%$ of the words were noted by hand. Of this small percentage, only $5 \%$ were abbreviated. Moreover, an analysis of variance on the percentage of abbreviations during notetaking yielded a significant medium effect. By contrast, in the PP condition, $25 \%$ of the words were abbreviated $(F(1,58)=43.42$, $p<.001)$. Irrespective of the type of medium, the analysis indicated that the students always abbreviated more words in $\mathrm{L} 1$ than in $\mathrm{L} 2(\mathrm{~F}(1,58)=12.91, \mathrm{p}<.001$; see Table 5$)$.

An analysis of variance on the number of ideas noted by the participants revealed an effect of medium (mean $P P=14$; mean $W P=28 ; F(1,58)=35.21, p<.001$ ). The interaction of this factor with language was also significant $(F(1,58)=8.17, p<.01)$. In the PP condition, the participants noted significantly more ideas in $L 1$ (mean=15.8) than in $L 2$ (mean=12; $F(1,30)=6.85$, $p<.02$ ), whereas the opposite was observed in the WP condition (mean $L 1=23$; mean $L 2=32$; $F(1,28)=4.41, p<.05$; see Table 5). 
Table 5: Percentage of noted words that were abbreviated, number of ideas noted, by language and medium.

\begin{tabular}{|c|c|c|c|}
\hline & $\mathrm{PP}(\mathrm{sd})$ & WP (sd) & Mean \\
\hline \multicolumn{4}{|c|}{ Percentage of noted words abbreviated } \\
\hline L1 & $32(16)$ & $9(16)$ & $20(19)$ \\
\hline L2 & $18(7)$ & $1(3)$ & $10(10)$ \\
\hline \multicolumn{4}{|c|}{ Number of ideas noted } \\
\hline L1 & $16(4)$ & $23(10)$ & $19(8)$ \\
\hline L2 & $12(2)$ & $32(15)$ & $22(14)$ \\
\hline
\end{tabular}

Sd: the standard deviation is shown in parentheses.

\section{Writing Processes}

Concerning the quantity of the ideas written, no main effect of the factors studied was observed. On the other hand, the analysis of the ideas derived from notes revealed a significant interaction between medium and language $(F(1,58)=4.80, p<.04)$. In the PP condition only, participants used significantly more of their notes to write the letter in $L 2$ than in $\operatorname{L1}(F(1,30)=11.12, p<.01$; see Table 6). The difference between the two languages was not significant in the WP condition.

Table 6: Number of ideas written in the letter and percentage of ideas derived from notes taken, by language and medium.

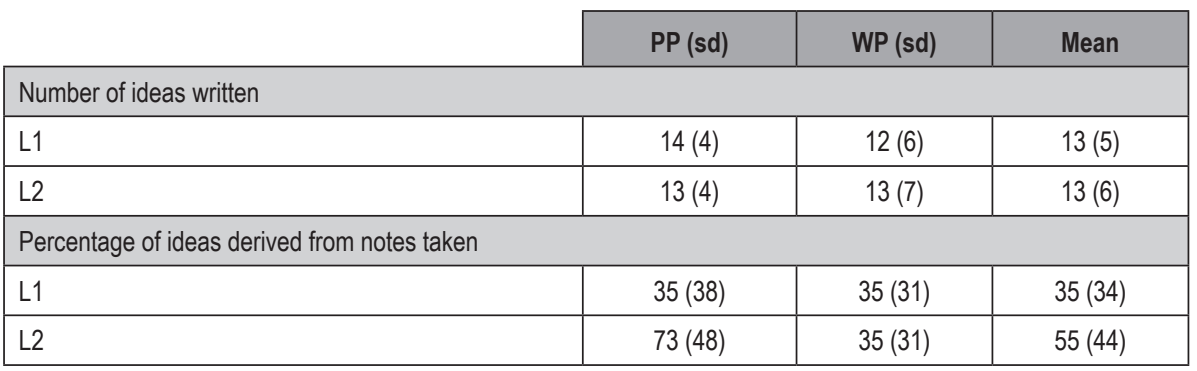

Sd: the standard deviation is shown in parentheses. 
Descriptive empirical studies

\section{Discussion}

This research was primarily aimed at studying the attentional load entailed by reading, notetaking, and writing from an electronic document in L1 and in L2. The second aim was to analyze the processes implemented in website exploration and notetaking, depending on the language and mediums used. Concerning cognitive effort, surprisingly, there was no significant difference between the two languages. On the other hand, reading and notetaking were significantly more costly than writing. This initial result contradicts those of previous studies by Barbier and Piolat (2005) and Piolat et al. (2005), which showed for the pen-andpaper medium, that notetaking was less costly than writing. To understand this inconsistency, the nature of the writing task has to be taken into account. Within the framework of previous studies, writing was done without notes, so as to evaluate the relative cost of each activity. Consequently, the recalling and planning processes took place during writing. In the present study, writing was deliberately done in more natural conditions, i.e. those probably used in an actual context of using notes. One of the consequences is that idea-generating comes into play as early as the notetaking stage. Writing therefore consists of recopying and formulating ideas, thereby reducing the associated cognitive cost. Note also that in this study, the reaction times observed during reading and notetaking from the electronic document in the pen-and-paper condition were comparable to those observed in Gérouit, Piolat, Roussey, \& Barbier (2001). In that earlier experiment, reaction times on computer reading were significantly longer than those observed during reading from a paper document. Thus, the nature of the tool seems to have significant impact on the cognitive cost of the activities observed. In the present study, the cost associated with the use of an electronic document was already very high in L1, so this was all the more true in $\mathrm{L} 2$.

Because notetaking was done with a word processor, the cognitive cost associated with reading was found to drop significantly in both languages. This result is no doubt due to the strategy implemented by the participants: they almost exclusively used the copy and paste function to retrieve information from the website. Indeed, with the word processor, only $10.5 \%$ of the words were noted using the keyboard. The number of words noted per minute was also very high in this situation. Everything seems to suggest that the notetakers retrieved the largest amount of information possible by putting off the selection of relevant information. Given that the reaction times associated with the notetaking and writing task were not longer because of this, we can assume that the participants benefited from this situation by allocating their cognitive resources to idea selection as they were carrying out the experimental tasks.

With regard to website exploration, the results confirmed that the dominant strategy for notetaking in the word-processor condition, was retrieving the greatest amount of information possible. The notetakers explored the website more thoroughly, browsing and returning to more pages, and they spent more time on each page. In this situation, there was no significant difference between notetakers across languages. By contrast, in the paper condition, L2 notetakers did not have the same attitude as L1 notetakers; they seem to have developed a compensatory strategy to overcome linguistic difficulty. They searched more actively for information in the different website pages, but this strategy had consequences, given the time allotted to the task. 
On the whole, while the L2 participants navigated on more pages, they tended to spend less time exploring the information presented in those pages than $\mathrm{L} 1$ participants.

When taking notes by hand (which is the case in the paper condition), the notetakers in the two languages did not use the same processes. Participants abbreviated almost twice as many words noted in $\mathrm{L} 2$ than in $\mathrm{L} 1$. This result is comparable to that observed in previous research (Barbier \& Piolat, 2005; Faraco et al., 2002). Again, the ways of abbreviating in L1 were apparently not transferred to $L 2$, and the use of this process seems to entail the acquisition of language-specific conventions (Barbier, Faraco, Piolat, \& Branca, 2004). Nonetheless, word abbreviation in notetaking is an effective strategy for saving time and transcribing as many words as possible without having to go back to the source document.

The linguistic difficulties of the L2 notetakers were also identified in the paper condition by the fact that fewer notes were taken. Compared to notetakers in L1, L2 participants did more verbatim copying of their notes during the writing process. In contrast, the L2 participants benefited from the word-processor condition, since they were able to copy and paste far more ideas than the L1 participants, as if they sensed the difficulty of selecting relevant information. The dependent variables defined here do not allow us to judge the quality of the texts produced. But in the end, with the word-processor, the L2 participants managed to select ideas, and even to be more creative in their final writing, since they produced more new ideas compared to their notes, like the L1 participants did.

To conclude on the main results obtained here, it appears that resource allocation in working memory depends on the nature of the task. Whatever the language, reading and notetaking from the experimental website were more costly than writing, especially since this does not constitute an important stage of idea generation. Surprisingly, no reaction-time difference was observed between L1 and L2. In this study, however, information on most of the content pages was presented in a basically linear mode rather than in a spatial mode. These conditions do not make reading via screen any easier (Baccino, 2004), given that attention span already seemed to be at its maximum in L1. By using the copy and paste function almost exclusively to retrieve information from the website, participants working on the word processor succeeded in making reading a less costly activity, and they searched for information more actively throughout the entire website. Finally, the notetakers' inadequate mastery of L2 became apparent only in the paper condition: they explored the website pages less. In this situation, given that the L2 participants did not abbreviate as much as in L1, the number of ideas noted was also smaller during notetaking; to succeed in writing enough ideas, they did not take the time to transform the selected information during the initial reading. Conversely, use of the word processor seems to be beneficial to $L 2$ notetakers who performed quite similarly to the notetakers in L1.

On the whole, the effects observed on the variables studied here enable us to identify the potential sources of difficulty for students who will be required to take notes in L2 to earn their university degree. The data obtained support the view that learning a second language entails the acquisition of specific skills, not only in reading and writing, but also in notetaking, especially if done manually. They also show that, if learning is at stake, the type of tool used should be taken into account to foster the emergence of written skills in various contexts of language use. In this research, the word-processor condition seemed to markedly facilitate the notetaking 
Descriptive empirical studies

task of the L2 participants by allowing them to regulate their activity in a manner comparable to the $\mathrm{L} 1$ participants. This facilitation, however, does not tell us anything about the quality of the final text produced. From the standpoint of ergonomics, the results of this study point out the necessity, in all cases, of elaborating - and, above all, communicating - the ergonomic features which make on-screen reading less costly (see Baccino, 2004), and which should also help related activities such as notetaking for users working in L2. From a teaching perspective, this study led to conclude that both the type of task and the type of medium must be considered when developing lesson plans for teaching reading and writing on a computer. Regarding the type of task, we discussed the role of planning processes and their consequences on the cognitive resources allocated to the notetaking process. Regarding the type of medium, the use of a word processor for notetaking off a website does not involve the same strategies as on paper for selecting and using information later. In this medium, L1 and L2 strategies are more alike. Here, there are undoubtedly more opportunities for transferring L1 skills to L2. By contrast, notetaking by hand is much more resource-demanding (due to linguistic constraints). Thus, students should be taught the abbreviation conventions specific to L2 so that they can develop effective strategies for taking notes on paper.

Finally, this study was a first step toward defining online indicators that teachers could use to assess students' writing processes. The indicators defined in this study (number of pages browsed, percentage of website browsed, page exploration time, percentage of total time spent on table-of-contents pages, number of words noted) seem to be useful for analyzing the strategies of website users. There are certainly other indicators that need to be explored and adapted to classroom use by teachers, or even by students themselves (during selfevaluations, for example, Spellman-Miller, 2005). Whatever the case may be, research on the use of computers in class must include a thorough analysis of how teachers might use such indicators to help them detect students' writing difficulties. Further studies along this line could lead to the development of new tools for teachers.

\section{Acknowledgment}

The study presented in this article was supported by an $\mathrm{ACl}$ "Education and Training" (as part of the project entitled "Reading, Notetaking and Writing from Hypertexts: A Comparative Study of Production Modalities in First and Second Languages; 2004-2007) and by a NATO scholarship (as part of the project "Bilinguals' Long-Term Working Memory Strategies During L2 Notetaking"; Collaborative Linkage Grant, reference LST.CLG.979517). 
Baccino, T. (2004). La lecture électronique [The electronic reading]. Grenoble: PUG.

Barbier, M.-L. (2006). Coût de l'exploration d'un site web en L2? [cognitive load of web exploration in L2]. In A. Piolat (Ed.). Lire, écrire, communiquer et apprendre avec Internet [Reading, writing, communicating and learning with Internet] (pp.151-172). Marseille: Editions Solal.

Barbier, M.-L., Faraco, M., Piolat, A., \& Branca, S. (2004). Prise de notes et procédés de condensation en français $L 2$ par des étudiants anglais, espagnols et japonais [Note-taking and abbreviation procedures in French L2 by English, Spanish, and Japanese students]. In N. Andrieux-Reix, S. Branca, \& C. Puech (Eds.). Ecriture abrégées (notes, notules, messages, codes...). L'abréviation entre pratiques spontanées, codifications, modernité et histoire [Abbreviatory writing] (pp. 143-161). Gap: Editions Orphys.

Barbier, M.-L., \& Piolat, A. (2005). L1 and L2 cognitive effort of notetaking and writing. In L. Alla, \& B. Schneuwly (Eds.). Proceedings at the SIG Writing Conference 2004 [CD-ROM]. Geneva: Switzerland.

Barbier, M.-L., Piolat, A., \& Roussey, J.Y. (1998). Effet du traitement de texte et des correcteurs sur la maîtrise de l'orthographe et de la grammaire en langue seconde [Effect of the word processor and the spelling and grammar checkers in second language]. Revue Française de Pédagogie, 122, 83-98.

Barbier, M.-L., Piolat, A., Roussey, J-Y., \& Olive, T. (2006). Notetaking in second language: Language procedures and self-evaluation of the difficulties. Current Psychology Letters. Brain, Behavior and Cognition, 20(3). [http://cpl.revues.org/]

Blondel, F.M., Le Touzé, J.C., \& Tarizzo, M. (2002). ARI: un assistant logiciel pour accompagner la formation à la recherche d'informations [ARI: a software to assist training in search of information]. In Frasson, C., \& Pecuchet, J.P. (Eds.), Actes du Colloque TICE2002, INSA, Lyon, November 2002, pp. 167-174.

Chaudron, C., Loschky, L., \& Cook, J. (1994). Second language listening comprehension and lecture note-taking. In J. Flowerdew (Ed.), Academic listening: Research perspectives (pp. 75-92). Cambridge: Cambridge University Press.

Clerehan, R. (1995). Taking it down: notetaking practices of L1 and L2 students, English for specific purposes, 14(2), 137-157.

DeStefano, D., \& LeFevre, J.O. (2007). Cognitive load in hypertext reading: a review. Computers in Human Behavior, 23(3), 1616-1641.

Faraco, M., Barbier, M.-L., \& Piolat, A. (2002). A comparison between L1 and L2 notetaking by undergraduate students. In S. Ransdell \& M.L. Barbier (Vol. Eds.), \& G. Rijlaarsdam (Series Ed.), Studies in Writing: Vol. 11. New Directions in Research on L2 Writing (pp. 145-167). Dordrecht: Kluwer Academic Publishers.

Gérouit, C., Piolat, A., Roussey, J.-Y., \& Barbier, M.-L. (2001). Coût attentionnel de la recherche d'informations par des adultes sur hypertexte et sur document papier [Cognitive load of information research by adults on hypertext and on paper document]. In M. Mojahid \& J. Virbel (Eds.), Actes du $4^{\circ}$ Colloque International sur le Document Electronique (pp.201215). Paris: Europia Production. 


\section{REFERENCES}

Titsworth, B.S., \& Kiewra, K.A. (2004). Spoken organizational lecture cues and student notetaking as facilitators of student learning. Contemporary Educational Psychology, 29, 447461.

Hannon, B., \& Daneman, M. (2001). A new tool for measuring and understanding individual differences in the component processes of reading comprehension. Journal of Educational Psychology, 93, 103-128.

Olive, T., Kellogg, R.T., \& Piolat, A. (2002). The triple task technique for studying the processes of writing: Why and How? In T. Olive \& C. M. Levy (Eds.), Contemporary tools and techniques for studying writing (pp. 31-59). Dordrecht: Kluwer Academic Publishers.

Piolat, A., Olive, T., Roussey, J.-Y., Thunin, O., \& Ziegler, J.C. (1999). SCRIPTKELL: a tool for measuring cognitive effort and time processing in writing and other complex cognitive activities. Behavior Research Methods, Instruments, \& Computers, 31(1), 113-121.

Piolat, A., Olive, T., \& Kellogg R.T. (2005). Cognitive effort of notetaking. Applied Cognitive Psychology, 19, 291-312.

Piolat, A., Barbier, M.-L., \& Roussey, J.Y. (2008). Fluency and cognitive effort during firstand second-language note-taking and writing by undergraduate students. European psychologist, 13(2), 114-125.

Raby, F. (2005). A User-Centred Ergonomic Approach to CALL Research. In J. Elgert. G. Petrie (Eds.), CALL Research Perspectives (pp. 179-190). Mahwah, NJ: Lawrence Erlbaum Associates.

Rouet, J.F. (2003). La compréhension des documents électroniques [Understanding on electronic documents]. In Gaonac'h, D. \& Fayol, M. (Eds.), Aider les élèves à comprendre [Help learners to understand]. Paris: Hachette Education.

Desmette, D., Hupet, M., Schelstraete, M.A., \& Van der Linden, M. (1995). Adaptation en langue française du « Reading Span Test » de Daneman et Carpenter (1980) [French adaptation of the « Reading Span test » of Daneman et Carpenter (1980)]. L'Année Psychologique, 95, 459-482.

Friedman, N., \& Miyake, A. (2005). Comparison of four scoring methods for the reading span test. Behavior Research Methods, 37, 581-590.

Ross, S. (1998). Self-assessment in second language testing: a meta-analysis and analysis of experiential factors. Language Testing, 15, 1-20.

Spellman-Miller, K. (2005). Second language writing research and pedagogy : A role for computer logging ? Computers and Composition, 22, 297-317.

Van Waes, L., \& Leijten, M. (2006). Logging writing processes with Inputlog. In L. Van Waes, M. Leijten \& C. Neuwirth (Vol. Eds.), \& G. Rijlaarsdam (Series Ed.), Studies in Writing: Vol. 17. Writing and Digital Media (pp. 158-166). Oxford: Elsevier. 
Appendix : Examples of website sections

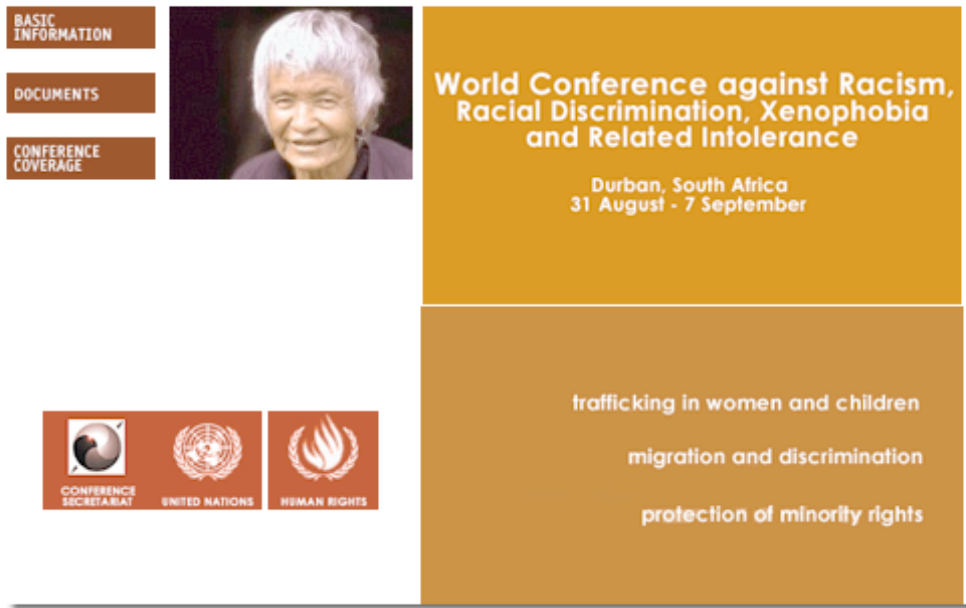

Prepared by the Information Technology Section, DPI $\otimes$ United Nations 


\title{
APPENDIX
}

World Conference against Racism

\section{Why a World Conference Now?}

"As we see all around us, racism and racial discrimination continue unabated. Although we refer to our worid as a giobal village, it is a world sadly lacking in the sense of closeness towards neighbour and community which the word village implies. In each region, and within all countries, there are probiems stemming from either a lack of respect for, or lack of acceptance of, the inherent dignity and equality of all human beings. Our world is withess to senous ethnic conficts; to discrimination against minonies, indigenous peopies and migrants workers, the accusation of insblutionalized racism in police forces, harsh immigration and asylum policies; hate sites on the Internet and youth groups promoting intolerance and xenophobia."

[Mary Robinson, United Nations High Commissioner for Human Rights, 24 March 1999]

\author{
| Meeting the challenge at the millenium | \\ IThe preparatory process I \\ Global action against racism \\ I The international year |
}

During the last fifty years since the adoption in 1948 of the Universal Declaration of Human Rights, the international community has made some important advances in the fight against racism, racial discrimination, xenoohobia and related intolerance. National and international raws have been enacted and numerous international human rights instruments, particularly a laws have been enacted and numerous international human rights instruments, particularly the defeat of apartheid in South Africa. Yet, the dream of a world free of racial hatred and bias remains only half fulfilled.

As technology brings the peoples of the world closer together and political barriers tumble, racial discrimination, xenophobia and other forms of intolerance continue to ravage our societies. Horrors such as "ethnic cleansing" have emerged in recent years, while ideas of racial superiority heve spread to new media ha the Internet. Even globalization carries risks that can lead to exclusion and increased inequality, very often along racial and ethnic lines.

As racial discrimination and ethnic violence grow in complexity, they become more of a challenge for the international community. As a result, new tools to deal with racism a called for. "This World Conference has the potential to be among the most significant gatherings at the start of this century," the Secretary-General of the Conference and High Commissioner for Human Rights, Mary Robinson, stated. "It can be more: it can shape and embody the spint of the new century, based on the shared conviction that we are al members of one human family." 


\section{Participation in the Conference}

The World Conference against Racism, as well as the sessions of its Preparatory Committee, are open to participation by:

- All Member States of the United Nations;

- All regional organizations and commissions involved in the preparation of regional meetings;

- Representatives of organizations which have received a standing invitation from the General Assembly to participate as observers;

- UN specialized agencies, regional commissions, bodies and programmes:

- Representatives of UN mechanisms in the field of human rights:

- Interested non-governmental organizations to be represented by observers, in accordance with UN Economic and Social Counci resolution 1996/31

- Other interested governmental organizations, to be represented as observers.

Basic information I Documents I Conference coverage 


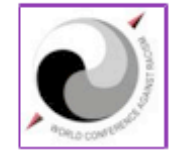

World Conference against Racism, Racial Discrimination, Xenophobia and Related Intolerance

\section{NOTE TO CORRESPONDENTS}

MEDIA ARRANGEMENTS FOR WORLD CONFERENCE AGAINST RACISM, RACIAL DISCRIMINATION, XENOPHOBIA AND RELATED INTOLERANCE.

Durban, South Africa

31 August - 7 September 2004

The World Conference against Racism will be beld at the International Convention Centre (ICC) from 31 August to 7 September. The building will be closed to the public during this period and access will be restricted to those persons who are accredited and wearing a United Nations World Conference grounds pass.

\section{Opening Day}

During the World Conference, access will be restricted at certain times, because of space $\propto$ security considerations. Coverage in the restricted areas will be arranged on a "pool" basis. For the opening day, access to the Plenary Hall will be restricted due to special security measures and space limitations. For the morning session tickets for seats in the press gallery will be issued starting at $8: 30$ a.m., and at 1:45 p.m. for the afternoon round table. Those will be issued on a first-come, first-served basis. All visual media coverage will be done by selected media pools and crews will be escorted by United Nations staff while in the ICC building. Members of the pools should gather at the Media Liaison office room M-4 in the Media Centre (Durban Exhibition Centre) at 7 a.m. to be screened and brought by a Liaison. Officer to the ICC for one of the three pool locations. Contact tel.: (031) 327-3944.

\section{Media Centre}

The Media Centre is located in the Durban Exhibition Centre. Inquiries should be directed to the Media Information counter, which will be staffed from 8 a.m. to 10 p.m. from Friday 31 August until Friday 7 September to assist journalists with both substantive and logistical questions. The telephone numbers at the Media Centre are + 27-31-327-3950/3952). The following technical services can be provided:

- Large screens carrying live proceodings of the plenary, press conferences and other events on closed circuit television;

- The audio of the plenary can be recorded in the original ("floor") language, English and French, using the mult-box set up in the room. Press conferences from the Coast of Dreams building can be recorded in English and other languages, when available, using the mult-box set up in the room;

- Paging system for general announcements to the media;

- Telephone services can be provided by Telkom on a commercial basis (credit cards required);

- Electrical cutlets (110 volts) are available in the Media Centre to enable journalists to use their laptop computers with modems:

- A limited number of computers with Internet access and printers are available:

- Fax machines are available on a commercial basis:

- The Information Desk and distribution counter will have copies of documents, press releases, speeches and other material. 